\title{
Research on the Countermeasures of China's Digital Agriculture Development*
}

\author{
Ye Zhao \\ Economics Department of Teaching and Research \\ Party School of Liaoning Provincial Party Committee \\ Shenyang, China
}

\begin{abstract}
As a new type of agricultural model, digital agriculture is a modern agricultural development mode that uses modern information technology to visualize, digitally design and informationize agricultural objects, environment and whole process. It is of great significance to realize the modernization of agriculture and rural areas. The overall progress of China's digital agriculture development is still lagging. In order to promote its development, it needs to start from the development model, the construction of talent team, the effective docking of small farmers and digital agriculture, and the integration and application of agricultural data.
\end{abstract}

Keywords—digital agriculture; agricultural modernization; rural revitalization

\section{INTRODUCTION}

The rural revitalization strategy proposes to accelerate the modernization of agriculture and rural areas in accordance with the general requirements of industrial prosperity, ecological livability, rural civilization, effective governance, and affluent living. Realizing rural revitalization and industrial prosperity is the foundation. The prosperity of rural industries does not simply refer to agricultural development, but refers to the comprehensive development of rural industries, and the development of agriculture is the most important prerequisite. China is one of the birthplaces of world agriculture. It has been the largest agricultural country in the world since the 19th century. It should be said that China's agriculture has made great achievements, but compared with the rapid development of industrialization, informationization and urbanization, agricultural modernization is still a short board. As far as ethnic areas are concerned, due to the factors of resource endowment and location, the degree of agricultural mechanization, industrialization and informatization is low, and modern agricultural development is lagging behind. Therefore, how to develop modern agriculture is the key link to achieve rural revitalization. The "Several Opinions of the Central Committee of the Communist Party of China and the State Council on Adhering to the Priority Development of

*Project: This article was funded by the "Xingliao Yingcai Project" "Research on the Quality Development of Liaoning Province Finance in the New Era", the project number is: XLYC1807200; this paper is the phased research result of Liaoning Province's "100 Million Talent Project" candidate project "Research on the Evaluation and Transformation of Liaoning Urban Social Assistance Policy in the New Era".
Agriculture, Rural Areas and Rural Residents" issued in February 2019 proposed a digital rural strategy, in which the development of digital agriculture as an important way to achieve agricultural modernization. As a new type of agricultural model, digital agriculture is a modern agricultural development mode that uses modern information technology to visualize, digitally design and informationize agricultural objects, environment and whole process. It is of great significance to realize the modernization of agriculture and rural areas.

\section{THE IMPORTANCE OF DEVELOPING DIGITAL AGRICULTURE IN CHINA}

\section{A. The Development of Digital Agriculture Is an Inevitable Requirement for Deepening the Adjustment of Agricultural Industrial Structure}

There are two problems in China's agricultural development. First, the cost of agriculture continues to rise. Since China's accession to the World Trade Organization, the cost of China's major agricultural products has been on the rise, and it has now surpassed the United States comprehensively and substantially. From the total cost per $\mathrm{mu}$ of agricultural products, the data in 2015 showed that China's corn, rice, and soybeans were $56.05 \%, 20.82 \%$, and $38.44 \%$ higher than those in the United States, while wheat and cotton were $210.42 \%$ and $222.84 \%$ higher than the United States. The rising cost has led to the occupation of major agricultural products markets by imported agricultural products. Second, the quality of medium and high-end agricultural products needs to be improved. From the perspective of agricultural planting structure, the planting area of the main varieties of corn, which cannot meet the market demand and cannot meet the market demand, still accounts for a high proportion; from the perspective of agricultural product processing, the depth precision is insufficient to meet the high-level market demand. The rough processing of processed products is much less, the finishing is less; the primary products are more, the deep processing products are less; the middle and low grade products are more, and the high-grade products are less. The consequence is that the primary processing products are faced with fierce market competition and lack of profitability due to insufficient features, while the high-end market has problems of defect site. And through the development of 
digital agriculture, the comprehensive benefits and competitiveness of agriculture must be improved by adjusting the agricultural supply structure.

\section{B. Developing Digital Agriculture Can Increase the Total Factor Productivity of Agriculture}

Digital agriculture can improve the economic efficiency and market competitiveness of agriculture by increasing land output rate and labor productivity. This efficiency improvement is based on advanced production conditions, infrastructure and modern material equipment, especially the transformation of traditional agriculture with modern technology. The United States has adopted a large-scale mechanized farming method under the land resources and factor endowments of a small population. As early as the end of the 1920s, it basically completed the mechanized farming of large-scale agricultural products in the field, and realize the transformation of agricultural production methods from labor-intensive to capital-intensive and technology-intensive, thereby increasing the level of comprehensive agricultural productivity.US agriculture sustains and supports the development of manufacturing industries that have a "preharvest" and "post-harvest" effect on agriculture. Currently, the output value of the sector providing services to agriculture, accounts for about two-thirds of the value of the entire service industry in the United States. The division of labor, in turn, has created conditions for the improvement of overall agricultural productivity in the United States.

\section{The Development of Digital Agriculture Can Promote the Transformation of Smallholder Production to Differentiated Intensive Agriculture}

The development of modern agriculture is not in contradiction with the existence of small farmers. Small farmers mainly adopt family management methods in production, which makes it possible for elaborate management. In this respect, Japan and the Netherlands have many successful experiences. The fact that the Japanese have more land and less national conditions, has led to the development of agriculture as a mode of small-scale farming. However, its agricultural development strategy through differentiation and intensive farming has also realized the modernization of agriculture. In order to give full play to the demonstration effect of comprehensive agriculture, Japan has organized a number of leisure agricultural parks with holiday farms as the mainstay in the urban-rural integration department. The operation is carried out in accordance with the management model of ordinary parks, combining agricultural production, processing, training and internships. On the one hand, agriculture has many functions of production, practice, tourism, etc., on the other hand, it also plays a complementary role in urban and rural areas. The Netherlands is a country with a small arable land and a small agricultural population in Western Europe, but it has created $9 \%-10 \%$ of the world's agricultural output. The Dutch agricultural achievements are inseparable from its worldclass facility agriculture. More than $90 \%$ of the facility agricultural parks in the Netherlands are soilless, advanced circulating irrigation technology ensures stable nutrients in the matrix, and a precise water supply control system can adjust the water supply of crops according to the growth cycle and solar radiation. This ensures the need for crop growth and avoids wasting water. The value of small farmers lies in their diversity and refinement, and the development of informatization has made it possible for smallholder production to transform into differentiated intensive agriculture. For example, the model of Internet + physical farms helps to improve the standardization and technology level of smallholder production. The development of rural ecommerce helps to achieve the connection between small farmers and diverse market needs; creative agriculture, experience agriculture and other modes of sharing economics helps to expand the multiple values of small farmers

\section{The Development of Digital Agriculture Can Promote Innovation in Management Methods in the Agricultural Sector}

Modern agriculture makes the industrial chain of agriculture tighter through advanced management methods, management techniques and management methods, while stable and efficient sales and processing channels can organize scattered farmers into an efficient modern organizational system. For example, the Indian government carried out the "white revolution" in the 1970s to promote the development of agriculture. The "white revolution" made India the world's largest milk producer. In the white revolution, India effectively organized the scattered farmers through the innovation of the management system, which stimulated the power of the public and private sectors in India, and avoided competition within the cooperatives at all levels to form a competitive force and advantage. Among them, the complete milk production and marketing threelevel cooperative network centered on dairy farmers has realized the specialized management of production, acquisition, processing and sales; the dairy farmers as the shareholder of the cooperative can greatly improve the enthusiasm of the dairy farmers; the professional cooperative managers have raised the level of specialization in milk brand planning and marketing.

\section{E. The Development of Modern Agriculture Can Promote the Combination of Agriculture and Environmental Protection to Develop Sustainable Agriculture}

The sustainability of agriculture should use production technologies and production models such as eco-agriculture, organic agriculture, and green agriculture to promote the establishment of a virtuous ecosystem of agricultural regions. Agriculture can achieve industrial upgrading through the combination of ecology and environmental protection. Taking the development of adoption agriculture as an example, with the improvement of living standards, the demand for agricultural products by the public is not only abundant but also superior. In this case, the "adoption agriculture" that combines agriculture and environmental protection has emerged. "Adoption Agriculture" adopts the model that consumers prepaid production costs. The producers are ecologically active throughout the production process, using farmyard manure, and adopting physical 
control technologies such as insect nets and insecticidal lamps to ensure the safety of the entire input, and to provide consumers with green and organic food. In this way, a production mode of risk sharing and revenue sharing is established between producers and consumers, and the direct docking of land to the table is realized. At the same time, the income of farmers is also significantly improved. Under the "adoption agriculture" model, the income increased in the case of a decline in the yield per mu, up to 5,500 yuan, which in turn enabled farmers to increase their income.

\section{RESEARCH ON THE COUNTERMEASURES OF DIGITAL AGRICULTURE DEVELOPMENT IN CHINA}

From the development of digital agriculture in China, since the pilot in 2017, digital agriculture has covered the production, circulation, service, and consumption of agriculture. There are vertical agricultural materials and ecommerce in the pre-harvest. In the production, there are mainly agricultural big data services, plant protection drones, etc., and there are agricultural products e-commerce and traceability of agricultural products in circulation. Although China's digital agriculture is developing at the same time, it also can be seen that the overall progress of China's digital agriculture development is lagging behind. It is also necessary to promote the development of digital agriculture from the following aspects.

\section{A. Combining Local Characteristics with Local Conditions to Choose the Development Model of Digital Agriculture}

Agricultural production is affected by many factors including natural factors, agricultural productivity, industrial policies, and market demand, etc., which leads to obvious regional differences in agricultural production. At present, the development of digital agriculture in China is very unbalanced. For example, Beijing, Xinjiang, Heilongjiang and other northern regions have relatively high application levels due to early start and good foundation. Therefore, the application level is relatively high, while Shanghai, Jiangsu, Guangdong and other East China and South China regions are relatively late to start, and the foundation is weak, so the application level is low. This reality determines that the development model of digital agriculture cannot be the same. The development process of digital agriculture from abroad also fully reflects this law. In the United States, Australia, Canada and other countries, due to the shortage of people and the shortage of labor, digital agriculture has chosen a development model that uses agricultural machinery to increase agricultural productivity and total agricultural output. In the Netherlands and Israel, due to the scarcity of resources and the scarcity of resources, the development of digital agriculture has chosen the development model of facility agriculture led by high value-added greenhouse and horticultural crops. Because of the characteristics of scarcity of cultivated land in Japan, its digital agriculture has chosen each region to have industrial characteristics, and each farmer has a development model of leading products; thus it can be seen that the development model of digital agriculture must be combined with regional characteristics to suit local conditions. For areas with better agricultural development, the output and quality of agricultural production can be improved through the application of modern agricultural technology and new species. For example, the development of the modern agricultural wisdom garden model, that is, the application of agricultural information technology as the core, vigorously promotes the application of the Internet of Things in agricultural production. For areas with a general agricultural development base, some flexible digital technologies can be introduced and developed according to local characteristics. For example, the development of precision agriculture mode refers to the precise and accurate adjustment of various agronomic measures in accordance with the environmental conditions of each operating unit in the field and the spatial and temporal differences in crop yields in order to obtain the highest yield and maximum economic benefits. For areas where China's cultivated land resources are scarce, they can rely on "technical output + financial services" to develop digital agriculture. For example, the development of digital agricultural loans and other modes means the application of big data calculation and professional farming knowledge to accurately put funds into the industrial chain, thereby maximizing the efficiency of capital use. At the same time, it will be necessary to strengthen the complementarity and unity between the regions, and jointly strengthen a strong digital agricultural team through a complementary and joint approach to technology, combining a strong digital agriculture team to improve overall competitiveness.

\section{B. Strengthening the Construction of Talent Team and Training New Farmers to Adapt to the Development of Digital Agriculture}

The degree of development of digital agriculture is closely related to the quality of agricultural workers. However, most of the agricultural workers in China are farmers aged 50 or so. The level of knowledge is low and the ability to receive high technology is weak. This situation directly affects the development of digital agriculture. Therefore, it is necessary to cultivate a multi-level new professional peasant team that adapts to the development of digital agriculture. It should cover the following three levels: The first level concludes the produce and business type farmers who mainly plants large-scale breeding households, family farmers, backbones of farmers' professional cooperatives, etc.; the second level concludes the professional skilled farmers who are traditional peasant transformation professionals, migrant workers who have obtained various agricultural skills after returning to work, returning to military workers, or returning to rural areas. the third level concludes social service-oriented professional farmers with agricultural information workers, animal and plant epidemic prevention or quarantine officers, and agricultural product brokers as the main body. Based on this, the content of professional farmers at different levels and formulate targeted training programs will be enriched. At the same time, the system of professional farmers' registration, title recognition, and information file registration will gradually establish and improved to facilitate management, training and support. 


\section{Accelerating the Effective Docking of Small Farmers and Digital Agriculture}

As a basic production and operation unit of agricultural production in China, small farmers will exist for a long time in the future. This kind of reality determines that China cannot develop the model of digital agriculture in Europe and the United States and can only adopt the development path of leading enterprises + third-party production service systems. Under the condition of not changing the household contract responsibility system, agricultural leading enterprises will organize families of scattered households through contractual relationship with farmers, providing a practical way for small farmers to develop digital agriculture. The agricultural productive service industry can realize the effective integration of technology, information, capital, talents and other factors with the agricultural industrial chain, solve some common service problems in the process of smallholders' decentralized production and management, and realize the organic connection between small farmers and digital agriculture. However, from the current actual situation, the development of both leading enterprises and agricultural production services has yet to be strengthened. The leading enterprises of agricultural industrialization services have developed the "enterprise + farmer" model, the "enterprise + intermediary organization + farmer" model, the "enterprise + intermediary organization joint + farmer" model, and the "association + enterprise + intermediary organization consortium + farmers" mode and many other modes. However, in the process of actual driving, there are still many problems such as imperfect distribution mechanism, obvious regional differences in the role of leading enterprises, and not prominent role of industry associations. Nevertheless, the development of agricultural productive service industry has many problems such as imperfect system, single service content and inadequate service management. Therefore, on the one hand, the development of digital agriculture should cultivate and expand leading enterprises to improve the level of agricultural industrialization and digitization. On the other hand, it is necessary to speed up the establishment of a thirdparty production service system covering the entire industry chain.

\section{Accelerating the Integration and Application of Agricultural Data}

The key to digital agriculture lies in the acquisition, processing, analysis and application of agricultural data. However, from the basic situation of agricultural big data in China, there are problems of insufficient quantity and low quality. The emergence of this situation is caused by many reasons. On the one hand, due to the vast characteristics of China, the collection of agricultural big data is difficult. On the other hand, the information island phenomenon caused by the dispersal of agricultural big data in the land, agriculture, water conservancy, meteorology and other departments has made the data mining analysis more difficult, so it is necessary to increase the integration of agricultural data. From the perspective of coverage, it is necessary to gradually expand to the relevant upstream and downstream industries with the agricultural sector as the core; from the geographical perspective, it should include national, provincial, and even municipal data; in terms of breadth, it need to includes statistical data as well as basic information about the economic entities involved in agriculture. On the other hand, it is necessary to speed up the exploration and analysis of data for more fields, such as big data-based meteorological analysis modeling and forecasting, agricultural big data service platform supporting full industry chain services, agricultural product price trend and market saturation analysis based on big data, data-driven precision agricultural operations, data realization of agricultural product traceability, data restructuring supply chain and many other aspects.

\section{CONCLUSION}

The development of digital agriculture is an inevitable trend in realizing the modernization of China's agricultural and rural areas, and it is also an inevitable path for rural revitalization. In the development model, it is necessary to adapt to local conditions. For areas with better agricultural development, the production and quality of agricultural production can be improved through the application of modern agricultural technology and new species. For areas with a general agricultural development base, some flexible digital technologies can be introduced and developed according to local characteristics. For areas with severely scarce cultivated land resources in China, digital agriculture can be developed based on "technical output + financial services". In the talent team, a multi-level new professional peasant team that adapts to the development of digital agriculture should be cultivated. Based on this, the professional peasants at different levels need to be enriched and cultivated, and targeted breeding programs need to be formulated. At the same time, the system of professional peasant registration, title recognition, and information file registration need to be gradually established to facilitate management, training and support. In the connection between small farmers and digital agriculture, it is necessary to establish a third-party production service system covering the entire industrial chain while cultivating and expanding leading enterprises to enhance the level of agricultural industrialization and digitization. In the integration and application of agricultural data, it is necessary to increase the integration of agricultural data and accelerate the analysis of data mining.

\section{REFERENCES}

[1] Research Group of Ministry of Agriculture, Zhang Hongyu, Key Tasks and Realization Paths of Rural Industry Development with Chinese Characteristics [J]. Way of Seeking, 2018 (2). (in Chinese)

[2] Yan Wei, Talking about the Current Situation of Agriculturalization in China and the Development Trend of Agricultural Machinery Technology [J]. Science and Technology \& Innovation, 2016 (24). (in Chinese)

[3] Quan Shiwen, etc. On the Excessive Capitalization of Rural Land in China [J]. Chinese Rural Economy, 2018 (7): 2 - 18. (in Chinese)

[4] Han Tianfu, On the Ten Major Relationships in the Building of Modern Agricultural Industry R\&D System in China [J]. Management of Agriculture Science and Technology, 2008 (3). (in Chinese) 
[5] Tu Lichao, etc. Reflection on the Construction and Development of the Modern Agricultural Industry Technology System [J]. Hubei Agricultural Sciences, 2018 (11). (in Chinese)

[6] Xiong Lei, Hu Shiqi, The Path of the Organic Connection between Small Farmers and Modern Agriculture Development: Chongqing Case [J]. Contemporary Economic Management, 2019 (3). (in Chinese)

[7] CPC Central Committee, State Council. Rural Revitalization Strategic Plan (2018-2022)

[EB/OL].http://society.people.com.cn/n1/2018/1025/c1008

30361400.html. (in Chinese) 